\title{
Kajian terhadap Gerakan Kebangkitan Epistemologi (Epistemological Movement): Scientific Revolution Thomas S. Kuhn
}

\author{
Asep Supriyadi ${ }^{1}$, Nanat Fatah Natsir ${ }^{2}$, Erni Haryanti ${ }^{3}$ \\ 1,2,3Universitas Islam Negeri Sunan Gunung Djati Bandung, Indonesia \\ E-mail: asepktr@gmail.com, nanatfatahnatsir@uinsgd.ac.id,erni_hk@uinsgd.ac.id
}

\begin{tabular}{l}
\hline Article Info \\
\hline Article History \\
Received: $2021-12-27$ \\
Revised: $2022-01-22$ \\
Published: 2022-02-01
\end{tabular}

Keywords: Epistemology; Scientific; Revolutions; Thomas S. Kuhn.

\begin{abstract}
This study describes the study of the epistemological movement: the scientific revolution of Thomas S. Kuhn. The method used in this study uses a library research method or approach, that library research can be interpreted as a series of activities related to the methods of collecting library data, reading and taking notes and processing research materials. The results of this study indicate that Thomas S. Khun's thinking can be implemented in science, from existing studies at least it can be in the form of the following: (1) The importance of the history of science in every scientific discussion. History is important because it can explain scientific mistakes in the past. An example is the revision of the heliocentric concept. (2) Researchers or scientists should use a certain paradigm in conducting studies and research. As has been discussed and explained that the paradigm is a certain way of looking at something. This paradigm can be used as an instrument in a study. Sometimes the existing normal science has been different from the current conditions. So that the paradigm in a subject of study is different. Therefore, a new paradigm is needed in scientific studies. (3) Thomas S. Khun's line of thinking contributes to science that science can be revised and even revolutionized. Science is not a static thing but dynamic. Therefore, in its implementation, a science must always be developed and reviewed again according to the times so that the existing paradigm is a new paradigm that is in accordance with current conditions.
\end{abstract}

\begin{tabular}{l}
\hline Artikel Info \\
\hline Sejarah Artikel \\
Diterima: 2021-12-27 \\
Direvisi: 2022-01-22 \\
Dipublikasi: 2022-02-01
\end{tabular}

Kata kunci: Epistemologi; Scientific; Revolution;

Thomas S. Kuhn.

\section{PENDAHULUAN}

Ilmu pengetahuan menjadi masalah terpenting bagi kehidupan manusia, hal ini menjadi ciri manusia karena manusia senantiasa bereksistensi, tidak hanya berada seperti batu atau rumput yang berada di tengah lapangan, tetapi
Penelitian ini menjelaskan tentang kajian terhadap gerakan kebangkitan epistemologi (epistemological movement): scientific revolution Thomas S. Kuhn. Metode yang digunakan dalam kajian ini menggunakan metode atau pendekatan kepustakaan (library research), bahwa studi pustaka atau kepustakaan dapat diartikan sebagai serangkaian kegiatan yang berkenaan dengan metode pengumpulan data pustaka, membaca dan mencatat serta mengolah bahan penelitian. Hasil penelitian ini menunjukkan bahwa pemikiran Thomas S. Khun dapat diimplementasikan dalam ilmu pengetahuan, dari kajian yang telah ada paling tidak dapat berupa hal sebagai berikut: (1) Pentingnya sejarah ilmu dalam setiap pembahasan keilmuan. Sejarah penting karena dapat menjelaskan kesalahan-kesalahan ilmiah di masa lampau. Sebagai contoh adalah revisi akan konsep heliosentris. (2) Para peneliti atau ilmuan hendaknya menggunakan paradigma tertentu dalam melakukan kajian maupun penenlitian. Sebagaimana telah dibahas dan diuraikan bahwa paradigma merupakan sebuah cara pandang tertentu terhadap suatu hal. Paradigma ini dapat digunakan sebagai alat instrumen dalam sebuah kajian. Terkadang ilmu normal (norman science) yang ada telah berbeda dengan kondisi kekinian. Sehingga paradigma yang ada dalam sebuah subjek kajian pun berbeda. Oleh karena itu, maka diperlukan paradigma baru (new paradigm) dalam kajian keilmuan. (3) Alur berfikir Thomas S. Khun memberikan konstribusi bagi ilmu pengetahuan bahwa ilmu dapat direvisi bahkan direvolusi. Keilmuan tidak menjadi hal yang statis melainkan dinamis. Oleh karena itu, dalam implementasinya, sebuah keilmuan harus senantiasa dikembangkan dan ditinjau ulang kembali disesuaikan dengan zaman sehingga paradigma yang ada merupakan paradigma baru yang sesuai dengan kondisi kekinian. mengada. Oleh karena itu, manusia berbudaya, mengembangkan ilmu pengetahuan dan menggunakannya untuk kehidupan pribadi dan lingkungannya yang telah mereka antisipasikan (Wiramihardja, 2007), salah satu ciri khas manusia adalah sifatnya yang selalu ingin tahu 
tentang peristiwa-peristiwa yang terjadi di alam sekelilingnya (Supriani, 2022), keinginan tadi dapat bersifat sederhana, yaitu ingin tahu tentang "Apa" (Ontology), baik namanya kelompoknya maupun sifat-sifatnya. Tetapi keingintahuan tadi dapat juga bersifat kompleks, yaitu bila ingin mengetahui "Bagaimana" peristiwa tersebut terjadi (Epistemiologi); "Untuk apa" (Aksiologi) peristiwa tersebut kita pelajari. Ketiga landasan baik landasan ontology, epistemiologi dan aksiologi merupakan ciri spesifik dalam penyusunan pengetahuan. Bila usaha keingintahuan tadi berhasil maka diperoleh apa yang kita katakana sebagai ketahuan atau pengetahuan (knowledge).

Ilmu dengan filsafat sukar dipisahkan, oleh karena itu perlu ada keterpaduan anatara filsafat dan ilmu pengetahuan. Kadangkala Pembuktian empirik kurang mendapat perhatian dan metode ilmiah tampaknya belum berkembang, sedikit demi sedikit dengan makin berkembangnya penalaran dan metode ilmiah, dengan makin kuatnya dan makin dihargainya pembuktian empirik, dan seiring dengan itu, makin meluasnya penggunaan instrumen penelitian, satu persatu cabang-cabang ilmu mulai melepaskan diri dari filsafat, definisi ilmu bergantung pada sistem filsafat yang dianut, sedangkan sewaktu posisi ilmu lebih bebas dan lebih mandiri, definisi ilmu umumnya didasarkan pada apa yang dikerjakan oleh ilmu itu dengan melihat metode yang digunakannya. Berkembanglah ilmu-ilmu alamiah (natural sciences) dan ilmu-ilmu sosial (social science) (Ulfah, 2022). Astronomi, anggota ilmu-illmu alamiah, merupakan salah satu ilmu yang pertama-tama melepaskan diri dari filsafat, sedangkan psikologi, anggota ilmuilmu sosial, termasuk yang terakhir melepaskan diri dari filsafat (Semiawan., 2005), tidak dapat juga dipungkiri ilmu yang terspesialisasi itu semakin menambah sekat-sekat antara satu disiplin ilmu dengan disiplin ilmu yang lain, sehingga muncul arogansi ilmu yang satu terhadap ilmu lain. Tugas filsafat diantaranya adalah menyatukan visi keilmuan itu sendiri agar tidak terjadi bentrokan antara berbagai kepentingan (Bakhtiar, 2004).

Dalam revolusi ilmu pengetahuan ada seorang tokoh yang sudah mashur karena tuliasannya yakni Thomas S Khun, semakin tersohor dan banyak diapresiasi oleh para ilmuan setelah menulis buku the structire of scientific revolution, menurut Kuhn seorang ilmuan selalu bekerja dengan paradigma tertentu. Paradigma itu memungkinkan sang ilmuan untuk meme- cahkan kesulitan yang muncul dalam rangka ilmunya, sampai muncul begitu banyak anomali yang tak dapat dimasukkan dalam kerangka ilmunya, dan menuntut revolusi paradigmatik (Darmawan, 2021).

Jasa Kuhn sebenarnya terletak pada pendobrakan citra filsafat ilmu sebagai logika ilmu, serta menggulingkan anggapan seakan ilmu sebagai kenyataan yang mempunyai kebenaran sui generis (objektif dan satu-satunya), dengan itu Kuhn menyatakan bahwa ilmu pengetahuan tak terlepas dari faktor ruang dan waktu. Begitu banyak diapresiasinya pemikiran Thomas S Khun dalam Ilmu pengetahuan, terutamanya dalam hal paradigma dan sejarah ilmu, maka dalam penelitian ini menjadi penting pembahasan terkait pemikiran Thomas S Khun dalam hal revolusi ilmu pengetahuan.

\section{METODE PENELITIAN}

Sesuai dengan karakteristik masalah yang diangkat dalam penelitan ini maka menggunakan Metode Riset kualitatif yaitu menekankan analisanya pada data deskriptif berupa kata-kata tertulis yang diamati, pendekatan kualitatif penulis gunakan untuk menganalisis kajian jaring laba-laba, interaksi-interkoneksi Universitas Islam Negeri Sunan Kalidjaga Yogyakarta, maka dengan sendirinya penganalisaan data ini lebih difokuskan pada Penelitian Kepustakaan (Library Research), yakni dengan membaca, menelaah dan mengkaji buku-buku dan sumber tulisan yang erat kaitannya dengan masalah yang dibahas. Metode yang digunakan dalam kajian ini menggunakan metode atau pendekatan kepustakaan (library research), menurut Zed dal-am (Rahayu, 2020) bahwa studi pustaka atau kepustakaan dapat diartikan sebagai serangkaian kegiatan yang berkenaan dengan metode pengumpulan data pustaka, membaca dan mencatat serta mengolah bahan penelitian.

1. Objek Penelitian

Dalam penelitian ini objek penelitian terdiri dari 2 (dua), yaitu objek formal dan objek material (Arifudin, 2018). Objek formal dalam penelitian ini berupa data yaitu data yang berhubungan dengan tinjauan kritis kajian terhadap gerakan kebangkitan epistemologi (epistemological movement): scientific revolution Thomas S. Kuhn. Sedangkan objek materialnya berupa sumber data, dalam hal ini adalah tinjauan kritis kajian terhadap gerakan kebangkitan epistemologi (epistemological movement): scientific revolution Thomas S. Kuhn. 
2. Waktu Penelitian

Penelitian ini dilaksanakan pada bulan Oktober sampai dengan Desember tahun 2021.

3. Teknik Pengumpulan Data

Pengumpulan data yang dilakukan dengan menggunakan teknik dokumentasi yaitu mengadakan survey bahan kepustakaan untuk mengumpulkan bahan-bahan dan studi literatur yakni mempelajari bahan-bahan yang berkaitan dengan objek penelitian. Teknik pengumpulan data menurut (Bahri, 2021) mengemukakan bahwa merupakan langkah yang paling strategis dalam penelitian karena tujuan untama dari penelitian adalah mendapatkan data. Terdapat beberapa cara atau teknik dalam mengumpulkan data, diantaranya adalah observasi dan dokumentasi. Sumber data yang digunakan dalam penelitian ini mencakup data primer dan sekunder. Menurut (Hanafiah, 2021) bahwa data primer adalah data yang dikumpulkan langsung dari individu-individu yang diselidiki atau data tangan pertama. Sedangkan data sekunder adalah data yang ada dalam pustaka-pustaka. Data primer dalam penelitian ini adalah bukubuku terkait tinjauan kritis kajian terhadap gerakan kebangkitan epistemologi (epistemological movement): scientific revolution Thomas S. Kuhn dan data sekunder didapatkan dari jurnal-jurnal baik nasional maupun internasional.

\section{Alat Pengumpulan Data}

Dalam penelitian ini penulis akan menggunakan metode dokumentasi sebagai alat untuk pengumpul data karena penelitian ini adalah penelitian kepustakaan. Dengan kata lain, menurut (Juhji, 2020) bahwa teknik ini digunakan untuk menghimpun data-data dari sumber primer maupun sekunder.

5. Teknik Analisis Data

Analisis data tidak saja dilakukan setelah data terkumpul, tetapi sejak tahap pengumpulan data proses analisis telah dilakukan, penulis menggunakan strategi analisis "kualitatif", strategi ini dimaksudkan bahwa analisis bertolak dari data-data dan bermuara pada kesimpulan-kesimpulan umum. Berdasarkan pada strategi analisis data ini dalam rangka membentuk kesimpulan-kesimpulan umum analisis dapat dilakukan menggunakan kerangka pikir "induktif". Menurut (Sugiyono, 2015) bahwa metode pembahasan menggunakan metode deskriptif-analisis, yaitu menjelaskan serta mengelaborasi ide-ide utama yang berkenaan dengan topik yang dibahas, kemudian menyajikannya secara kritis melalui sumber-sumber pustaka primer maupun skunder yang berkaitan dengan tema.

6. Prosedur Penelitian

Data pada penelitian ini dicatat, dipilih dan kemudian diklasifikasikan sesuai dengan kategori yang ada, pendekatan yang digunakan adalah pendekatan deskriptif analitis. Menurut (Arifudin, 2019) bahwa deskriptif analitis (descriptive of analyze research), yaitu pencarian berupa fakta hasil dari ide pemikiran seseorang melalui cara mencari, menganalisis, membuat interpretasi serta melakukan generalisasi terhadap hasil penelitian yang dilakukan. Prosedur penelitian ini adalah untuk menghasilkan data deskriptif yang berupa data tertulis setelah melakukan anaisis pemikiran (content analyze) dari suatu teks. Setelah penulis mengumpulkan bahanbahan yang berhubungan dengan masalah yang akan dibahas dalam penelitian ini, kemudian penulis menganalisis dan menarasikan untuk diambil kesimpulan.

\section{HASIL DAN PEMBAHASAN}

Dalam pembahasan ini akan dibahas tentang Biografi Thomas S. Khun, latar belakang munculnya pemikiran Thomas S. Khun, Arus Utama Konsep Pemikiran Thomas S. Khun dan Implementasi Konsep Revolusi Ilmu Pengetahuan Bagi Keilmuan.

1. Biografi Thomas S. Khun

Untuk mengetahui latar belakang kemunculan Thomas S Khun serta pemikirannya, maka perlu diketahui terlebih dahulu biografinya, hal ini penting untuk melihat kehidupannya baik dari sisi pendidikan formal, pemikiran serta lingkungan yang mempengaruhinya maupun karya-karyanya, dengan demikian, maka akan dapat dilihat gambaran yang utuh tentang Thomas S Khun. Thomas Samuel Kuhn lahir pada tanggal 18 Juli 1922 di Cincinnati, Ohio, Amerika, putera dari Samuel L Kuhn. Ayahnya adalah seorang Insinyur industri dan mantan Annette Stroock pada tahun 1943 beliau mendapat gelar Sarjana Muda, Gelar Master yang dapatkan pada tahun 1946. Kemudian pada tahun 1949 Kuhn menerima gelar Ph.D dibidang fisika dari Hardvard University dan di sana ia diangkat sebagai Asisten Professor di bidang Pendidikan Umum dan Sejarah Ilmu.

Pada tahun 1956 ia menjadi Dosen di University of California, Barkeley. Kemudian 
pada tahun 1961 ia menjadi Professor penuh dalam bidang sejarah ilmu, dan pada tahun 1964 mendapat gelar Professor dalam bidang filsafat dan sejarah ilmu di Universitas Princeton. Pada tahun 1979 ia kembali ke Boston, dan saat itu pula ia diangkat sebagai Professor Filsafat dan Sejarah Ilmu di Massachussets Institute of Technology. Kuhn mendapat banyak penghargaan di bidang akademik, sebagai contohnya dia memegang posisi sebagai Lowel Lecturer pada tahun 1951, Guggeheim fellow dari 1954 hingga 1955. Pada tahun 1982 Kuhn mendapat penghargaan George Sarton Medal di bidang Sejarah Ilmu dan mendapat gelar Honorary dari beberapa Institut, seperti Columbia University dan beberapa universitas lain seperti Notre Dame, Chicago, Padua, Athena, dan lain sebagainya. Kemudian pada tahun 1983 Kuhn kembali dikukuhkan sebagai Professor, Khun diangkat sebagai pemegang rekor pertama dalam bidang filsafat dan sejarah ilmu, dan pada tahun 1991 dan pensiun dengan tetap memegang predikat Professor Emeritus. Karya Kuhn cukup banyak namun yang paling terkenal dan mendapat banyak sambutan dari filsuf ilmu dan ilmuwan adalah The Structure of Scientific Revolution, sebuah buku yang terbit pada tahun 1962. Buku tersebut banyak direkomendasikan sebagai bahan bacaan dalam kursus dan pengajaran berhubungan dengan pendidikan, sejarah, psikologi, riset dan sejarah serta filsafat sains, disamping itu juga, buku tersebut dapat diakses secara global karena sudah ada versi pdf nya di internet.

2. Latar belakang munculnya pemikiran Thomas S. Khun

Karya yang paling banyak mendapat sorotan dari para ilmuan adalah bukunya yang berjudul the structure of scientific revolution pada tahun 1962. Buku ini merupakan hasil dari laporan dan proyek yang dipikirkannya selama kurang lebih 15 tahun, buku inilah yang mengantarkan Thomas S khun banyak diapresiasi dalam ilmu pengetahuan, terlebih dalam bidang filsafat ilmu, penelitian dan sejarah ilmu. Buku tersebut lebih banyak menyoroti terkait ketiga hal tersebut (Kuhn, 1962), dalam hubungannya dengan filsafat ilmu dan penelitian, ia menulis sub judul the priority of paradigm, the route to normal science, the nature of normal science, normal science as puzzle-solving, dan masih banyak lagi sub bab lainnya. Berkaitan dengan sejarah ilmu, ia menulis sub bab introduction: a role for history yang ia tulis di bagian awal (Suparlan, 2018).

Konsep pemikirannya bermula dari ketertarikannya dibidang filsafat ilmu, untuk mewujudkan ketertarikannya tersebut, ia mengikuti Junior Fellow of the Society of Fellows of Harvard University selama tiga tahun, dalam waktu tersebut Khun dedikasiakan waktunya untuk mendalami sejarah ilmu, disamping itu Khun juga melanjutkan mempelajari tulisan Alex andre koyre, Emile Meyerson, Hélène Metzger, and Anneliese Maier. Tulisan-tulisan mereka memiliki pengaruh bagi Thomas S Khun, para ilmuan tersebut membuka ketertarikan bagi Thomas S Khun dalam berfikir secara ilmiah disaat norma ilmu pengetahuan berbeda dengan kondisi sekarang.

3. Arus Utama Konsep Pemikiran Thomas S. Khun

Thomas S. Khun dikenal dengan bapaknya revolusi ilmiah, arus utamanya adalah revolusi ilmu pengetahuan, Thomas S. Khun menitik beratkan pada dua hal yakni sejarah ilmu dan paradigma, dengan demikian arus utama dari Thomas S. Khun adalah revolusi ilmiah dengan mengedepankan dan mementingkan sejarah ilmu dan paradigma dalam kerja ilmiah (Kuhn, 2000). Khun sangat menitik beratkan pada sejarah ilmu. Sehingga tidak heran apabila di bagian awal bukunya ia menuliskan introduction: a role for history. Hal ini merupakan penekanan Thomas S. Khun akan pentingnya sejarah ilmu. Tahun 1950-an, ketika Kuhn memulai studi sejarah ilmu pengetahuan, sejarah ilmu pengetahuan masih muda dalam disiplin akademis. Meskipun demikian, itu menjadi jelas bahwa perubahan ilmiah tidak selalu langsung sebagai standar, sebagaimana pandangan tradisional. Thomas Samuel Kuhn mula-mula meniti karirnya sebagai ahli fisika tetapi kemudian mendalami sejarah ilmu. Lewat tulisannya, The Structure of Scientific Revolutions (1962), ia menjadi seorang penganjur yang gigih yang berusaha meyakinkan bahwa titik pangkal segala penyelidikan adalah berguru pada sejarah ilmu. Sebagai penulis sejarah dan sosiolog ilmu kuhn mendekati ilmu secara eksternal. Kuhn dengan mendasarkan pada sejarah ilmu, justru berpendapat bahwa terjadinya perubahan-perubahan yang berarti tidak pernah 
terjadi berdasarkan upaya empiris untuk membuktikan salah (falsifikasi) suatu teori atau system, melainkan berlangsung melalui revolusi-revolusi ilmiah.

Gagasan Thomas Kuhn ini sekaligus merupakan tanggapan terhadap pendekatan Popper pada filsafat ilmu pengetahuan. Menurut Kuhn, popper memutar balikkan kenyataan dengan terlebih dahulu menguraikan terjadinya ilmu empiris melalui jalan hipotesis yang disusul dengan upaya falsifikasi. Namun Popper justru menempatkan sejarah ilmu pengetahuan sebagai contoh untuk menjustifikasi teorinya, gagasannya yang sangat radikal dan progresif tersebut kiranya berasal dari pengalaman ilmiah yang pernah dihadapinya sendiri. Pada tahun 1947 Kuhn diminta untuk mengajar mekanika klasik abad ke 17, maka kemudian ia membaca mekanika Aristotelian yang melatar belakangi perkembangan mekanika Galilei dan Newton. Dia sangat heran dan sering tidak percaya bahwa mekanika Aristotelian inilah yang mendasari lahirnya mekanika Galilei dan Newton yang sangat termasyhur di abad ke-17, dia menilai bahwa mekanika aristotelian mengandung kesalahan yang kemudian direvisi oleh Galilei kemudian Newton. Pengalaman inilah yang menjadi cikal bakal yang memunculkan gagasannya mengenai revolusi ilmiah. Revolusi ilmiah dimengerti oleh Kuhn sebagai episode-episode perkembangan nonkumulatif dimana paradigma yang lama digantikan seluruhnya atau sebagian oleh pradigma baru yang tidak dapat didamaikan dengan paradigma sebelumnya. Paradigma menurut kuhn mencakup hal berikut ini:

a) Model yang berdasarkanya muncul sejumlah tradisi penelitian ilmiah tertentu yang terpadu (koheren).

b) Pencapaian (hasil-hasil) ilmiah yang diakui secara universal yang untuk suatu masa tertentu menawarkan model, masalah dan solusi kepada komunitas pemraktek.

c) Hampir merupakan pandangan dunia, yakni cara memandang dunia melalui kacamata yang disediakan oleh cabang ilmu tertentu.

d) Terdiri atas sejumlah teori dan teknik khusus yang sesuai bagi pemecahan masalah-masalah penelitian.

e) Perpaduan teori dan metode yang bersama-sama mewujudkan sesuatu yang mendekati suatu pandangan dunia. f) Matriks disipliner, yakni keseluruhan konstelasi sejumalah keyakinan, generalisasi simbolik, model, nilai, komitmen, teknik, dan eksemplar yang dianut dan mempersatukan para anggota komunitas ilmiah tertentu.

g) Eksemplar, yakni penyelesian (solusi) tekateki atau masalah ilmiah yang dugunakan sebagai model atau contoh, dan yang dapat menggantikan aturan eksplisit sebagai landasan untuk solusi teka-teki lainnya dari ilmu normal; eksemplar ini dihasilkan oleh penelitian yang sukses yang kemudian digunakan oleh para pemraktek sebagai model.

Dengan demikian, para ilmuan yang penelitiannya didasarkan pada paradigma yang sama, pada dasarnya terikat pada aturan dan standar yang sama dalam mengemban ilmunya. Keterikatan pada aturan dan standar ini adalah prasyarat bagi adanya ilmu normal. Jadi secara umum dapat dikatakan bahwa paradigma itu adalah cara pandang atau kerangka berpikir yang berdasarkan fakta atau gejala diinterpretasi dan dipahami. Jadi, ilmu normal sebenarnya tidak terlalu memerlukan aturan atau metode yang standar (yang disepakati oleh komunitas ilmiah). Tanpa aturan dan metode yang baku, ilmu normal dapat berjalan, ini berarti bahwa setiap ilmuan dapat menciptakan aturan dan metode penelitian dan pengkajian sendiri sesuai dengan keperluan, sepanjang aturan dan metode ini diderivasi dari paradigma yang berlaku. Tetapi, jika paradigmanya belum mapan maka perangkat aturan akan diperlukan atau menjadi penting (Sidharta, 2008).

4. Implementasi Konsep Revolusi Ilmu Pengetahuan Bagi Keilmuan

Pemikiran Thomas S. Khun memiliki pengaruh yang besar bagi perkembangan ilmu pengetahuan, Khun menitikberatkan pentingnya sejarah ilmu dan pardigma dalam sebuah penelitian, kajian ilmiah, dengan sejarah ilmu, sebuah ilmu, temuan dapat diketahui kesalahan-kesalahannya dan dapat direvisi, dengan paradigma, seorang peneliti atau ilmuan dapat menggunakan pardigma tertentu dalam menyelesaikan masalah yang ada, disamping itu, pemikiran Thomas S. Khun dapat dijadikan landasan bagi pengembanagn ilmu pengetahuan tertentu yang kurang pas dengan kondisi sekarang, dengan adanya 
paradigma baru dalam sebuah kajian, oleh karena itu, Thomas S. Khun menitik beratkan pentingnya paradigma baru. Hal lain yang dapat diambil dari pemikiran Thomas S. Khun adalah struktur revolusi ilmu pengetahuan yang ia bangun. Ia menjelaskan bahwa ilmu pengetahuan pada mulanya berkembang normal, namun lama kelamamaan ada paradigma yang berbeda dengan ilmu normal sehingga terjadi anomali yang menyebabkan krisis. Oleh karena itu, krisis tersebut harus diselesaikan dengan paradigma baru. Inilah yang disebut revolusi ilmiah menurut Thomas S. Khun, dengan demikian Thomas S. Khun merumuskan sebuah struktur perkembangan ilmu pengetahuan dengan kronologis Pra ilmu-Ilmu-normal-Anomali-Krisis-Revolusi.

\section{SIMPULAN DAN SARAN}

\section{A. Simpulan}

Berdasarkan pemaparan pada penelitian kajian terhadap gerakan kebangkitan epistemologi (epistemological movement): scientific revolution Thomas $\mathrm{S}$. Kuhn ini dapat disimpulkan bahwa pemikiran Thomas S. Khun dalam revolusi ilmiah memberikan wacana pencerahan baru bagi para ilmuan modern. Setelah menulis The Structure of scientific revolution, Thomas $\mathrm{S}$. Khun banyak mendapat apresiasi dari kalangan para ilmuan. Dalam melakukan revolusi ilmu pengetahuan, ia menitikberatkan pada pentingnya sejarah ilmu dan paradigma. Dengan sejarah ilmu, sebuah ilmu atau temuan kajian dapat diketahui kesalahankeslahannya dan dapat direvisi bahkan direvolusi. Paradigma, bagi seorang peneliti atau ilmuan dapat digunakan sebagai intrumen dalam melakukan kajian. Terkadang paradigma lama sudah tidak sesuai dengan paradigma kekininian. Paradigma sebuah komunitas, masyarakat, suku maupun ras tertentu telah berbdeda dengan paradigma yang ada di normal scince. Oleh karena itu, maka perlu ada paradigma baru dalam kajian keilmuan. Dengan paradigma tersebut, sebuah ilmu akan dekat dengan realitas karena kajiannya didasarkan pada kondisi kekinian.

\section{B. Saran}

Pembahasan terkait penelitian kajian terhadap gerakan kebangkitan epistemologi (epistemological movement): scientific revolution Thomas S. Kuhn dalam penelitian ini masih sangat terbatas dan membutuhkan banyak masukan. Saran untuk penulis selanjutnya adalah mengkaji lebih dalam dan secara komprehensif terkait kajian terhadap gerakan kebangkitan epistemologi (epistemological movement): scientific revolution Thomas S. Kuhn.

\section{DAFTAR RUJUKAN}

Arifudin, 0. (2018). Pengaruh Pelatihan Dan Motivasi Terhadap Produktivitas Kerja Tenaga Kependidikan STIT Rakeyan Santang Karawang. MEA (Manajemen, Ekonomi, \& Akuntansi), 2(3), 209-218.

Arifudin, 0. (2021). Implementasi Balanced Scorecard dalam Mewujudkan Pendidikan Tinggi World Class. Edumaspul: Jurnal Pendidikan, 5(2), 767-775.

Bahri, A. S. (2021). Pengantar Penelitian Pendidikan (Sebuah Tinjauan Teori dan Praktis). Bandung : Widina Bhakti Persada.

Bakhtiar. (2004). Filsafat Ilmu (Cet. I). Jakarta: PT Raja Grafindo Persada.

Darmawan, I. P. A. (2021). Total Quality Management Dalam Dunia Pendidikan" Model, Teknik Dan Impementasi". Bandung: Widina Bhakti Persada Bandung.

Hanafiah, H. (2021). Pelatihan Software Mendeley Dalam Peningkatan Kualitas Artikel Ilmiah Bagi Mahasiswa. Jurnal Karya Abdi Masyarakat, 5(2), 213-220.

Irwansyah, R. (2021). Perkembangan Peserta Didik. Bandung : Widina Bhakti Persada.

Juhji. (2020). Manajemen Humas Sekolah. Bandung: Widina Bhakti Persada.

Kuhn. (1962). The Structure of Scientifc Revolution. Chicago: University of Chicago Press.

Kuhn. (2000). The Strukture of Scientific Revolotions. Penj. Tjun Surjaman. Bandung: PT. Remaja Rosdakarya.

Mayasari, A. (2021). Implementasi Sistem Informasi Manajemen Akademik Berbasis Teknologi Informasi dalam Meningkatkan Mutu Pelayanan Pembelajaran di SMK. JIIPJurnal Ilmiah Ilmu Pendidikan, 4(5), 340345. https://doi.org/10.54371/jiip.v4i5.277 
Nasser, A. A. (2021). Sistem Penerimaan Siswa Baru Berbasis Web Dalam Meningkatkan Mutu Siswa Di Era Pandemi. Biormatika: Jurnal Ilmiah Fakultas Keguruan Dan Ilmu Pendidikan, 7(1), 100-109.

Popper. (2008). The Logic of Scientific Discovery (Logika Penemuan Ilmiah), terj. Saut Pasaribu \& Aji Sastrowardoyo. Yogyakarta: Pustaka Pelajar.

Rahayu, Y. N. (2020). Program Linier (Teori Dan Aplikasi). Bandung : Widina Bhakti Persada.

Semiawan. (2005). Panorama Filsafat Ilmu Landasan Perkembangan Ilmu Sepanjang Zaman (Cet. I). Bandung: Mizan.

Sidharta. (2008). Apakah Filsafat Dan Filsafat Ilmu Itu (Cet. I). Bandung: Pustaka Sutra.

Sofyan, Y. (2020). Peranan Konseling Dosen Wali Dalam Meningkatkan Motivasi Belajar Mahasiswa Di Perguruan Tinggi Swasta Wilayah LLDIKTI IV. Jurnal Bimbingan Dan Konseling Islam, 10(2), 237-242.
Suparlan. (2018). Filsafat Ilmu Pengetahuan, Persoalan Eksistensi Dan Hakikat Ilmu Pengetahuan. Yogyakarta: Ar-Ruzz Media.

Supriani, Y. (2022). Peran Manajemen Kepemimpinan dalam Pengelolaan Lembaga Pendidikan Islam. JIIP-Jurnal Ilmiah Ilmu Pendidikan, 5(1), 332-338.

Ulfah, U. (2022). Kepemimpinan Pendidikan di Era Disrupsi. JIIP-Jurnal Ilmiah Ilmu Pendidikan, 5(1), 153-161.

Qadafy. (2014). Revolusi Ilmiah Thomas Samuel Kuhn (1922-1996) Dan Relevansinya Bagi Kajian Keislaman. Jurnal Al-Murabbi, 1(1), 4-7.

Wiramihardja. (2007). Pengantar Filsafat (Cet. II). Bandung: PT Refika Aditama. 